\title{
Educación al revés de la letra en las Lecciones Sexta y Séptima de los Grundzüge (1806)
}

\author{
Education on the back of the letter in the Sixth and Seventh Lessons \\ of the Grundzüge (1806)
}

\author{
Luciano Carlos Utteich \\ lucautteich@terra.com.br \\ (Universidade Estadual do Oeste do Paraná, Paraná, Brasil)
}

\begin{abstract}
Resumo: Fichte abordó en las Lecciones Sexta y Séptima de Los Caracteres de la Edad Contemporánea [Die Grundzüge des gegenwärtigen Zeitalters, 1806] una importante cuestión relativa al intervalo entre dos períodos o edades, la tercera y la cuarta edad de la humanidad, en su relación de oposición y complementariedad. Para él había llegado el momento de preparar la necesaria transición de la tercera a la cuarta edad de la humanidad, ya que la tercera representaba una falsa autonomía lograda por la letra (por la imprenta) frente al espíritu, siendo éste la verdadera fuente de vivacidad en los asuntos humanos desde su marco inicial, la comunicación oral. En nuestro texto contextualizamos brevemente el tema de los criterios de lectura que presupone la verdadera ciencia de la razón como requisito que apunta a este momento previo en el que la propia letra (discurso escrito o impreso) se genera en la dimensión del espíritu, como la actividad verdaderamente viva que satisface todas las necesidades del pensamiento, ya sea filosófico o literario, en la sociedad.
\end{abstract}

Palabras-claves: Doctrina de la Ciencia; educación; Espíritu; autonomía.
Abstract: Fichte deals, in the Sixth and Seventh Lessons of the Characteristics of the Present Age [Die Grundzüge des gegenwärtigen Zeitalters, 1806], with an important question concerning the interval between two periods or ages, the third and fourth ages of humanity, in its relation of opposition and complementarity. For him, the time had come to prepare the necessary transition from the third to the fourth age of humanity, since the third represented a false autonomy acquired by the letter (by the press) in relation to the spirit, which was the true source of vitality in human affairs from its initial setting, oral communication. We briefly contextualize the theme of the criteria of reading that the true science of reason presupposes in order to reach the fourth age of humanity, as a requirement that points to the elucidation of this moment before the letter itself (in written or printed discourse) in which oral communication is generated in the dimension of the spirit, as a truly living activity that meets the needs of thought, whether philosophical or literary, in society.

Keywords: Doctrine of Knowledge; education; Spirit; autonomy.

DOI: http://dx.doi.org/10.11606/issn.2318-9800.v25i2p193-221

«Para entender la regla es necesario entender el espíritu de ésta.» Stanley Ford Rous

\section{Introducción}

La escasez de trabajos sobre la filosofía de la historia de Johann Gottlieb Fichte, a pesar de su valor indudable, demuestra que no se le ha prestado la debida 
atención, si se compara con el respaldo de sus otras obras. La dificultad en integrarla en el conjunto de su obra se ha convertido en una tarea inacabada incluso para los comentaristas clásicos. ${ }^{1}$ No se debe entender por ende que ella desarrolle un papel de categoría menor. El reconocimiento de las bases que la mueven posibilita entenderla cómo no solo un enfoque histórico a más desde la filosofía, a la cual podría ser un competidor más, sino que, así como en las líneas generales por las cuales Fichte forneció en el mismo período su filosofía de la religión en La Exhortación a la vida bienaventurada [Anweisung zum seligen Leben], los datos que constituyen su estudio sobre la historia, aparentemente apartado de su sistema, pueden ser rastreados en el interior de lo propuesto al llevarse en cuenta la intención presentada por él en Los Caracteres de la Edad Contemporánea [Die Grundzüge des gegenwärtigen Zeitalters], una intención científica expuesta de manera popular, cuyos vínculos se remontan, tanto a sus obras tempranas (del primero Fichte, el de Jena) como a sus obras más maduras (el Fichte de Berlín). ${ }^{2}$

A su vez, delante de la crisis por la cual pasan hoy las propuestas de abordaje especulativa de la historia, ${ }^{3}$ arrojar luz sea de su propósito general, sea de sus partes constituyentes, interesa a nosotros en vista de demarcar la peculiaridad de esta concepción de la historia y hacia desentrañarla, en particular, el papel asignado a la Educación desde la diferencia entre espíritu y letra en el enfoque de la filosofía transcendental. Habiéndose considerado a sí mismo responsable de llevar adelante el legado de la filosofía kantiana, en su concepción de la historia Fichte se mantiene dentro de las pautas del método transcendental, alineado con el enfoque regulativo de Kant y en una síntesis muy propia del pensamiento de Herder. ${ }^{4}$ Fichte nunca

1 Uno de los principales, Reinhard Lauth, por ejemplo, afirmó: «El lugar de la doctrina de la historia no está claramente explicado en el sistema ideal de Fichte» (Lauth, 1962, p. 327, nuestra traducción). En cierto modo, este problema trajo consigo la dificultad de incorporar también la noción de naturaleza, aparentemente rechazada por Fichte (y entonces recuperada por Schelling). Esta modificación fue lograda por la interpretación de Helmut Girndt, que incorporó el pensamiento de la naturaleza y la historia en el esquema de la quintuplicación fichteana, colocándolos en su lugar en su sistema. Véase Girndt, 1990, pp. 108-120 y Girndt, 2002, pp. 253-262.

2 A diferencia de las lecciones teóricas, el enfoque de la historia y la religión está destinado a ser exposiciones aplicadas de la filosofía transcendental, es decir, tiene un propósito práctico en el sentido de ser una praxis. Dice Lauth: «si se proporciona al hombre no científico la ciencia aplicada empíricamente, entonces la comunicación teórica se vuelve popular. Sólo aquí está el sitio sistemático de lo popular, que tan a menudo se entremezcló con lo filosófico-aplicado» (Lauth, 1968, p. 45).

3 Esa crisis se ha revelado ruptura de uno de los últimos bastiones del ímpeto especulativo de la razón. Por ende, una primera cosa a atentar es a la distinción entre los diferentes enfoques filosóficos de la historia, los que caen en el ámbito de la más pura especulación racional y los que admiten sólo un principio regulador, no determinante. En línea con Kant, el enfoque fichteano de la historia encaja en la última propuesta, pues, cómo dice Fichte, «el concepto de un plan del universo es un supuesto de nuestra investigación, el cual, por la causa indicada, en modo alguno puede aquí derivar [abzuleiten], sino sólo señalar [anzuzeigen]». (GA, I/8, 198; Fichte, 1976, p. 24). Según una investigación necesariamente no determinante como la de la historia, Kant ya había declarado: «No tengo necesidad de demostrar esta suposición; es el adversario de ella quien ha de proporcionar una prueba» (Kant, 1923, 309; Kant, 1986, p. 54).

4 Para un debate más detallado sobre eso, véase Sisto, 2009a y Marín, 2019. 
trató de dirigir su pensamiento de modo subordinado y arbitrario al concepto de especulación, en comparación al que persiguió Hegel al proponerse un enfoque objetivo (lectura objetivizante) de la historia y que, por su fuerza, estandarizó la escena durante un largo período. ${ }^{5}$ Por lo contrario, buscó extraer las novedades del método transcendental de su maestro y aun insertó en ese método su propio modo a fin de facilitarle en claridad y mejorar su aprensión por los demás.

En ese contexto dos componentes tienen directamente relación al legado kantiano: primero el modo de tratar la historia solo desde un abordaje no determinante, sino solo regulativa; y secundo, el de la filiación de la necesaria reforma del pensamiento, requerida por Kant en el Respuesta a la pregunta: ¿qué es Ilustración?, ${ }^{6}$ con el primado de la razón práctica encabezado ahora en los moldes de Fichte, en un sentido más existencial y ontológico, mientras hace surgir la concepción de la acción humana «no del puro deber (o no solamente de él), sino de la necesidad existencial del ser», 7 como apuntó Oswaldo Market (1980, p. 116). Este carácter existencial de la voluntad puede verse ya en los añadidos de la edición danesa (publicada en 1796) de las Lecciones sobre el destino del sabio en que Fichte afirma: "Algo no es un bien para nosotros simplemente porque nos haga felices; sino, a la inversa, nos hace felices porque era un bien previo a nosotros, a nuestro sentimiento, a nuestra felicidad» (GA, I/3, 31; Fichte, 2002, p. 163). Ese elemento

5 Es interesante contrastar, por un lado, la lectura inmanente de la filosofía hegeliana de la historia $y$, por otro, el uso que hacen de ella sus herederos. En cuanto al primero vale las conclusiones de Martín Sisto, según las cuales, aún que «en la historia puede haber razón [...] que la historia sea racional es difícil de aceptar, al menos en cuanto la filosofía nos pretenda revelar su secreto», pues, completa él, «las graves limitaciones que padece el hombre tienen una razón de ser que escapa a nuestra comprensión» (Sisto, 2009b, p. 252). Para un amplio enfoque sobre la crisis del concepto de la historia desde el ocaso de la filosofía de Hegel, véase Schnädelbach, 1991.

6 Así como en el Respuesta a la pregunta: ¿qué es Ilustración? Kant tendrá en mente no al ser humano individual, sino a la especie (o sea, el ser que merece hacerse público), Fichte toma como base de la exposición narrativa hacia cada una de las cinco épocas el hombre como especie, y no como individuo. Y así como Kant subrayó que la revolución no puede hacer ningún bien para el desarrollo del hombre como especie, sino que sólo la reforma íntima (del modo de pensar) puede lograrlo, Fichte somete en el Grundzüge la elevación de la individualidad a la especie como medio de expresar la adopción de este camino de reforma, por la cual el hombre se vuelve a la idea, el concepto nuclear de los Grundzüge.

7 Según Market, la razón kantiana «como encarnación de nuestra autonomía, ha suprimido el fundamento objetivo, la ratio essendi», y al hacer eso "corre el riesgo de entrar en conflicto con el logos», por el hecho de solo salvar al «cómo [...] del conocimiento», y no al qué de él. (Market, 1980, p.114). Siguiendo a Market, la doctrina fichtiana del Bien, buscada mediante el primado práctico de la razón, hará entonces «una reimplantación del pensar en el Ser» (idem, p. 118), por lo cual se arrojará la luz a la nueva etapa de la metafísica de la voluntad en la Filosofía, no más de una voluntad como facultad apetitiva, sino como fundada por los impulsos (Trieben). En esa crítica vale la pena recordar a Ortega y Gasset: «Kant no se pregunta qué es o cuál es la realidad, qué son las cosas, qué es el mundo. Se pregunta, por el contrario, cómo es posible el conocimiento de la realidad, de las cosas, del mundo. [...] La filosofía moderna adquiere en Kant su franca fisonomía al convertirse en mera ciencia del conocimiento. Para poder conocer algo es preciso antes estar seguro de si se puede y cómo se puede conocer. [...] En esta tradición de la desconfianza, Kant representa la cima. No sólo fabrica de la precaución un método, sino que hace del método el único contenido de la filosofía. Esta ciencia del no querer saber y del querer no errar es el criticismo» (Ortega y Gasset, 1958, p. 7-11). 
previo a nosotros presenta la voluntad como deudora de la teoría del impulso [Trieb], mientras que, dice él, no es posible que surja un impulso hacia el objeto,

sólo en virtud de esta intelección teórica. [..] Éste, sin embargo, no es el proceder que hay que seguir, sino justamente el inverso. El impulso es lo primero y supremo en el hombre. El impulso reclama su objeto antes de cualquier tipo de conocimiento y antes de la existencia del objeto. Simplemente exige algo incluso si lo que exige no existe en absoluto. Lo que nos puede hacer y nos hará felices está determinado de antemano por nuestro impulso. Un don nos hace felices porque era un bien para nosotros antes de que lo recibiéramos. Así es como operan todos los impulsos humanos, los físicos y los morales (GA I/3, 31; Fichte, p. 163-165).

En la Lección Primera de los Grundzüge Fichte apunta a la tensión o paridad que hay en el instinto racional del individuo, dentro de lo cual se discuten el instinto del individuo propio y el instinto del individuo extraño, que, como una autoridad coactiva [zwingende Autorität] que usurpa de los derechos del impulso [Trieb] de la libertad personal, requiere la intermediación del impulso de liberarse del instinto racional como solución contra la intromisión de cualquier instinto extraño. Según él, es así que se despierta por la primera vez la razón [Vernunft]. Dice: «ante todo en su forma de impulso de la libertad personal, que no se rebela nunca contra la dulce violencia del propio instinto [Instinkt], por él amada, pero sí contra la intromisión de un instinto extraño que usurpa sus derechos» (GA, I/8, 200; Fichte, 1976, p. 26).

Ese tema conduce a una comparación con lo dilucidado en la segunda proposición de la Idea de una historia universal desde un punto de vista cosmopolita de $\mathrm{Kant}^{8}$, que trata del desarrollo de las disposiciones naturales humanas cuyo énfasis recae en que tal desarrollo hace verdaderamente diferencia solo en la especie, no en el individuo. Allí Kant apunta que son las generaciones las que dejan atrás una base para que cada uno continúe construyendo el edificio de la especie, por lo tanto, subyace en ellas un acto continuo que solo tiene lugar en vista de «todos los principios prácticos» (Kant, 1902, 18; Kant, 2008, p. 31) mientras que depende del hombre individual (la individualidad) necesariamente dominar esta herencia para hacerla suya, es decir, depende de él elevar su individuo a la especie, sea a partir de su arreglada y constante adaptación a ella, sea por una reforma íntima (de su modo de pensar) debido a la aplicación de los principios prácticos con consecuencias directamente existenciales.

Si se piensa ahora en poner en marcha la inmensa unidad de un plan general que subyace a todos los objetivos individuales se vislumbra en qué dirección los Grundzüge de Fichte imprimen una dinámica a la concepción conjunta de la realidad humana de un punto de vista práctico, de acuerdo con lo que era latente en el tema de la historia en Kant. Fichte introduce en la Lección Primera el tema del conjunto de todas las

8 Dice Kant: «En el hombre (entendido como la única criatura racional de la Tierra) aquellas disposiciones naturales, que se refieren al uso de la razón, no se desarrollan completamente en el individuo, sino en la especie» (Kant, 1902, 18; Kant, 2008, p. 30). 
secciones del libro (compuestas de diecisiete Lecciones) en que problematiza el modo por lo cual la humanidad llega a la ciencia de la razón (consciencia de la razón) como el paroxismo de todas las épocas [Zeitalter] de la vida de la humanidad en la tierra. Por un lado, semejante edad se refiere a uno de los extremos en que puede ser pensada la humanidad en su desarrollo lleno, a que se llamará la quinta edad, mientras que en ella «la especie [humana] vive y es» (GA, I/8, 198; Fichte, 1976, p. 24) tiendo organizado con libertad y según la razón todas las sus relaciones. Pero, por el otro extremo es justamente lo contrario: es el de la edad en que la vida da especie humana sobre la tierra ocurre «sin haber organizado todavía con libertad y según la razón sus relaciones» (GA, I/8, 198-199; Fichte, 1976, p. 24), en virtud de la cual esa queda caracterizada como la primera edad de la humanidad sobre la tierra.

Así, ese tema de las etapas de la vida humana en la tierra trata de los modos del pasaje del hombre, como especie, en las etapas intermediarias entre esos extremos; semejantes pasajes se constituyen por la segunda, tercera y cuarta edades. Nuestra edad actual se halla aún muy lejos de la quinta edad; a su vez estamos conscientes de que todo comenzó en la primera edad y la tarea filosófica es pensar como cada época se escindió desde el concepto unitario de la totalidad de la vida. (GA, I/8, 266; Fichte, 1976, p. 24) El propulsor para ejecutar o seguir esta ruta, que ya ocurrió por lo menos desde la primera hasta la edad actual (tercera edad) siempre se ha regido por la máxima que reza: «el fin de la vida de la Humanidad sobre la tierra es el de organizar en esta vida todas las relaciones humanas con libertad según la razón» (GA, I/8, 198; Fichte, 1976, p. 24). Del mismo modo esa máxima debe conducirnos adelante, pues la meta del hombre como especie y la su puesta en práctica implica llegar a concebir la especie como «una perfecta imagen de su eterno arquetipo en la razón», desde lo cual, completa Fichte, «se habría alcanzado el fin de la vida terrena, se habría llegado a su término, y la Humanidad pisaría las altas esferas de la eternidad» (GA, I/8, 200; Fichte, 1976, p. 26). Así, del modo asintótico nos aproximamos al acceso de la cuarta e la quinta edades.

Al par introduce Fichte para tema central de esas conferencias el de tratar los motivos por los cuales la humanidad se queda actualmente en la tercera edad, como en una transición hacia la cuarta edad, pero aún en el tratamiento de los dolores del alumbramiento de un tiempo que se avecina. Ese es el problema discutido en el interior de cada una de las diecisiete lecciones, haciendo del progreso de la especie humana un tema importante y a la vez desafiador en su registro por el filósofo transcendental. En eso consiste la exposición filosófica de la historia de la humanidad, dice Fichte: se trata de una visión de las cosas que «reduce una multiplicidad dada en la experiencia a la unidad del principio singular y común, y que, a la inversa, explica íntegramente por esta unidad todo lo múltiple y lo deriva de ella» (GA, I/8, 196; Fichte, 1976, p. 22). Para tanto presupone un concepto unitario del tiempo en que, dice él, 
cada miembro esté condicionado por el anterior; o [...] supone un plan del universo que se pueda concebir claramente en su unidad y partiendo del cual se puedan derivar íntegramente las épocas capitales de la vida humana sobre la tierra y se puedan comprender distintamente en su origen, así como en su conexión mutua (GA, I/8, 197; Fichte, 1976, p. 23).

Como las épocas capitales de la vida humana sobre la tierra, que asignan «los conceptos unitarios de cada edad determinada [...] de los cuales hay que derivar, a su vez, los fenómenos de ella» (GA, I/8, 197; Fichte, 1976, p. 23), desde ahí se establecen las cinco edades fundamentales, mientras que se adopta la noción subyacente de un plan del universo como «el concepto unitario de la totalidad de la vida humana» (GA, I/8, 197; Fichte, 1976, p. 23).

Así, escindido el concepto unitario de la totalidad de la vida en varias épocas, esas épocas - hay que así considerarlas - son concebibles unas con otras y unas por otras por medio de su conexión en la totalidad del tiempo (como el intervalo de los dos extremos), en virtud de lo cual se requiere entender, para comprender la etapa actual (tercera edad) y a cada una de ellas, siempre las inmediatamente anteriores. Pues, pregunta Fichte: «¿cómo podría la Humanidad ni siquiera querer liberarse de la ley de su vida [...] del instinto racional [natural]?» (GA, I/8, 199-200; Fichte, 1976, p. 25). O también: «¿cómo podría en la vida humana entrar en disensión y pugna consigo misma la razón una que habla en el instinto y que actúa igualmente en el impulso de liberarse de él?» (GA, I/8, 200; Fichte, 1976, p. 25). La contestación de Fichte es clara: la humanidad y la razón pueden realizar ambas las cosas, pero solo de modo mediato e indirecto. Por eso las cinco épocas se suceden unas a las otras y agotan la vida entera de la especie sobre la tierra. Son ellas:

1. Aquella en que las relaciones humanas, sin violencia ni trabajo, está ordenadas por el mero instinto racional. 2. Aquella en que este instinto, debilitado y expresándose aún solo en unos pocos elegidos, se convierte para todos, por obra de estos pocos, en una autoridad exterior y coactiva. 3. Aquella en que se rechaza esta autoridad y con ella la razón en la única forma en que existe hasta ahora. 4. Aquella en que entra en la especie la razón en la forma de la ciencia en general. Y 5 . Aquella en que a esta ciencia se socia el arte para dar con mano firme y segura a la vida una forma ajustada a la ciencia, y en que por medio de este arte se perfecciona libremente la organización de las relaciones humanas conforme a la razón, y se alcanza el fin de la vida terrena entera, y nuestra especie pisa las esferas superiores de un mundo distinto (GA, I/8, 243; Fichte, 1976, p. 69-70 [el subrayado es nuestro]).

En particular, esa es la tesis fundamental del texto fichteano: «la época acabada de mencionar en tercero término era aquella cuya característica nos propusimos trazar como tema principal de estos discursos, sospechando, según confesamos, que el tiempo presente se halla justamente en esta época» (GA, I/8, 243; Fichte, 1976, p. 70).

En efecto, Fichte la caracteriza de este modo: esta tercera edad, 
como declarado adversario de todo ciego instinto racional y de toda autoridad, sentaba [...] la siguiente máxima: no admitir como válido absolutamente nada más que lo que concibe - se entiende al punto, como el sano entendimiento humano ya existente y que ha heredado sin ningún esfuerzo ni trabajo propio» (GA, I/8, 243; Fichte, 1976, p. 70 [el subrayado es nuestro]).

Es decir, lo que simboliza y resume el total sistema de pensamientos y opiniones de esta edad es «el resultado forzoso de que pudiésemos sacar a la luz del día este entendimiento que le sirve como patrón de medida en todo su pensar y opinar» (GA, I/8, 243; Fichte, 1976, p. 70). Y acá recibe el concepto de razón una ampliación muy consistente visto que, en contraste a ella, se destacan las incongruencias y disonancias de una época determinada, que resiste a adaptarse a la razón, pues «la razón [...] se dirige siempre a la vida de la especie como especie», independiente de la forma del instinto o de la ciencia, es decir, «abolida y extirpada la razón, no queda nada más que la mera vida personal individual» (GA, I/8, 243; Fichte, 1976, p. 70).

El talón de Aquiles de esa tercera edad es a la vez esto que ella erige como su verdadero activo: sólo queda la vida individual para la tercera edad, es decir, «el mero, puro y nudo egoísmo» (GA, I/8, 243; Fichte, 1976, p. 70). En efecto, ¿cómo queda delante de eso el entendimiento? Queda uno innato y estático que «no puede ser absolutamente otra cosa, ni contener absolutamente ninguna otra cosa que la inteligencia suficiente para fomentar el provecho personal» (GA, 1/8, 244; Fichte, 1976, p. 70). Casi como si fuera generada una ley práctica para perpetuar máximas de validad exclusivamente subjetiva, el proceder en esa tercera edad tiene en vista «los medios para conseguir la conservación y el bienestar de la vida personal» encontradas sólo «por medio de la experiencia», ya que sobre eso no enseñan nada «ni un instinto, como en el animal, ni la razón, que tiene por solo fin la vida de la especie» (GA, I/8, 244; Fichte, 1976, p. 70). Por eso la única fuente del saber, como trazo fundamental de esa edad, es la experiencia.

En el entramado de los temas capitales de la filosofía - las ciencias, el arte, las relaciones sociales del hombre, la moralidad y la religión - tomados por el modo de ver de la tercera edad, presenta su carácter problemático al creer que solo por el criterio personal del individuo, sin apostar en uno de la especie, se pueda alcanzar resultados efectivos; al contrario, la tercera edad produce el opuesto al requerido por el principio de una vida racional: él requiere que todos sacrifiquen su vida personal a la vida de la especie, pues es así solo que la vida de la especie entra en la consciencia y se convierte «en fuerza e impulso en la vida del individuo» (GA, I/8, 244; Fichte, 1976, p. 71), cómo el principio que se exprime efectivamente como idea (Idee). Lo que distingue la vida racional de la irracional es el cumplimiento de este principio: «entre que se ponga la vida simplemente en lo personal y en ello se agote, o se la sacrifique a la idea» (GA, I/8, 244; Fichte, 1976, p. 71).

Como edad llenamente irracional por su contenido, la tercera edad se halla «enfrente del resto entero del tiempo, como el racional por el contenido en igual 
modo, sólo que cada vez en distinta forma exterior» (GA, 1/8, 244; Fichte, 1976, p. 71). Mientras eso la edad racional sale a la luz siempre desde formas constantes debido adoptar el contenido en su forma interior. Queda acá el acento que hallaremos en el tema de las Sexta y Séptima Lecciones, al cual nos interesa tratar aquí. Es desde la forma interior que se puede alcanzar no solo una claridad verdadera respecto a la materia que se envuelve la ciencia, sino que desde ella tiene que ser encarados todos los temas capitales de la filosofía, las ciencias, el arte, las relaciones sociales del hombre, la moralidad y la religión.

Abajo destacamos cómo se desarrolla un sentido distinto en la historia la perspectiva de las cosas desde el espíritu o desde la letra. Visto que la noción de razón [Vernunft] está presente siempre en el desarrollo de la historia [Geschichte], discutiremos en qué en el ámbito de la Educación el embate entre espíritu y letra aclaró la dimensión fundamental y original del pensamiento humano de lo cual se derivan todos sus productos, como las obras escritas, los periódicos y las actividades de la Imprenta. Es decir, si la comunicación oral tiene su primado de modo radical con relación a los productos humanos que aparezcan en la historia, se pregunta por los motivos de haber ocurrido actualmente la inversión entre lo producido por esa actividad originaria y los productos de ella. En seguida presentamos algunos principios del privilegio de la letra desde el punto de la separación histórica en el Cristianismo, por la diferencia de apropiación del mensaje del evangelio por los discípulos Juan y Pablo, enfrente al novedoso traído por el Protestantismo. Y concluimos con la profundización de la doctrina de Juan como la que puso en destaque, al contrario de las demás, el elemento de la comunicación interior como la forma por la cual la humanidad puede sentirse desde ya en vínculo estrecho con la única concepción posible de la creación y del creador, es decir, desde la idea, cuyo acceso se da solo por el espíritu. Para empezar, traemos en más detalle la caracterización fichteana de la época actual, también llamada de tercera edad.

\section{El elemento vacío de una edad sin espíritu: la Tercera época}

En el contexto del pasaje de la tercera edad hacia la edad siguiente se muestra relevante la posición de la libertad mientras que por ella es verdaderamente elucidado el significado de la razón: si esta fuera manifestada como exclusivo dominio del elemento del instinto [Instinkt] en la primera edad y por la conversión del instinto en una autoridad exterior y coactiva (segunda edad), por fin, por la recusa de esa autoridad y de la única forma de la razón en esas condiciones (aún no racionales) se estableció la tercera edad, delante de la cual resta aún a alcanzarse la época de la auténtica razón en la nueva edad, representadas por la cuarta y quinta edades.

Solo hay la tercera edad porque se ha pasado por la segunda; si en aquella hay una recusa de la autoridad en la única forma que la razón se había manifiesto antes, a saber, como fuerza ciega [blinder Kraft], eso no significa decir que por manifestarse 
como fuerza ciega no hay razón en lo que se sucedió o que nunca la hubo. Es que, en sentido auténtico, solamente si la libertad de la especie fue tomada después de haber sido promovida la razón en la forma de la ciencia en general, entonces la especie participa propiamente (conscientemente) de la razón.

En la Lección Quinta Fichte expuso más detalladamente su crítica a la tercera edad y a las faltas o problemas que ella trae consigo. Se trata de que ella presupone como válido solo aquello ya existente y aquello de lo que, sin cualquier esfuerzo o trabajo, es heredera. Pero, como resultado de esa carencia de esfuerzo - o contraesfuerzo cero delante de aquello del que es heredera - su carencia estriba en que admite como máxima «no admitir como válida absolutamente nada más que lo que ella concibe» (GA, I/8, 243; Fichte, 1976, p. 70), como un modo de pensar que hace con que impere la individualidad (vida personal individual) y sus idiosincrasias.

Este es un modo de pensar vacío y en que la razón ha sido extirpada, pues se refiere directa y de modo explícito a la falta de significación para ella de la expresión: «vida de la especie» (GA, I/8, 244; Fichte, 1976, p. 70); ahí el entendimiento sirve solo para promover el provecho personal. ¿Cómo es posible que ocurra al entendimiento operar de ese modo? Por el hecho de una clase de empirismo haber sido tomada como patrón del entendimiento, ya que viene de ahí «el elogio de la experiencia como la única forma del saber» a que alcanzó esa época (GA, I/8, 244; Fichte, 1976, p. 70).

A fin de vislumbrar dentro de esa edad actual la nueva edad es menester ponderar donde se asienta la idea de la especie, que en la primera edad se presentaba interiormente como instinto obscuro [dunkle Instinkt] y en la secunda edad, como suscitada exteriormente por una autoridad imperativa. Como un eslabón perdido a apuntar a la realización de la libertad por un salto, para diferenciar entre la vida irracional y la vida racional en general, en el sentido ya mencionado de la segunda proposición del texto kantiano (Idea de una historia universal desde un punto de vista cosmopolita) sobre el desarrollo de las disposiciones naturales de la especie en vista de su edificio como tal, eso significa la ciencia para la cuarta edad: la comprensión del significado de la idea (Idee), pues, «todo lo que puede haber en un espíritu humano es idea» (GA, I/8, 246; Fichte, 1976, p. 72).

La idea es el elemento necesario para tener acceso y entrar en la consciencia la vida de la especie (y convertirse con eso en fuerza e impulso en la vida del individuo). De modo breve, el modo de pensar según la idea - que es el de acordar con que el individuo se sacrifique a la especie - es un modo por lo cual la humanidad tendrá que pasar una vez (GA, I/8, 245; Fichte, 1976, p. 72). La tercera edad carece justamente de eso: ella mantiene para contenido de su época el elemento antirracional de la admisión de cada manifestación en lo tiempo como asumiendo una distinta forma exterior. Es decir, admite no haber cualquier racionalidad en lo que ocurre delante de sí en lo tiempo.

Pero, ni toda clase de pensamiento, pondera Fichte, puede llamarse idea [ldee]. De ahí que se debe distinguir entre los conceptos que llegan al entendimiento 
sin necesidad de ninguna experiencia (exclusivamente eso es la idea) de aquellos que llegan por el camino del hombre meramente sensible, que es lo que se toma propiamente por individualidad («la existencia sensible personal del individuo» (GA, I/8, 246; Fichte, 1976, p. 73)). La tesis de Fichte es que, por sus propias leyes, y sin ser determinado desde lo sensible, la idea una y eterna se revela - a cada individuo - en una nueva forma. O por otras palabras: se revela mediante la aniquilación de la individualidad sensible, a fin de llegar a determinar puramente por sí misma una individualidad original (individualidad ideal) (GA, I/8, 246; Fichte, 1976, p. 74).

En su relación con las demás edades, la tercera edad apunta entonces a un concepto vacío sobre cómo operar para el provecho de la especie, pues mantiene en su horizonte el sólo individuo y llega por eso al grado máximo de una forma vacía de ciencia o, como dice Fichte, llega a uno concepto del concepto, ya que le falta la «idea», la única materia con la cual la ciencia presenta un contenido. Ese concepto vacío o concepto del concepto significa que el pensamiento que sirve de materia es siempre solamente un concepto empírico, según lo cual va a juzgar y apreciar el método científico por la adopción exclusiva de su criterio (GA, I/8, 247; Fichte, 1976, p. 74). El problema gana acento cuando se colocan delante de ese criterio todas las producciones humanas: las ciencias, las artes, las relaciones sociales del hombre, la moralidad y la religión, como los trazos igualmente fundamentales de esa edad. Debido a ese criterio, queda más claro que la tercera edad opera todo mediante una inversión. Según Fichte, ella «cree que basta invertir exactamente lo falso para llegar a la verdad» (GA, I/8, 248; Fichte, 1976, p. 74), a través de lo cual considera estar en condiciones de alcanzar la sabiduría. Es cierto que aquellos que lo piensan así son productos de esa misma edad: ellos parten de esa edad, más exprimen a la vez una reacción de esa edad contra si propia, donde la vaciedad de la máxima a que se aplican. No están seguros cómo solo la quinta edad podrá garantir mientras la edad en que la ciencia en general va de mano con el arte [Kunst] y en que actúan vida y ciencia en conjunto, donde las organizaciones humanas conforme la razón se perfeccionan por medio del arte.

Al contrario, actuando en contra a la idea (como lo que «da una inmensa fuerza y energía», pues solo de ella «emana la fuerza») (GA, I/8, 249; Fichte, 1976, p. 75), hacía la especie una edad que carece de ideas hará un desdoble de las fuerzas (disposiciones) solo de un modo débil y lánguido y alcanzará de modo superficial a los objetos de conocimiento, pues «será arrastrada por la ciega inclinación de la asociación de ideas» (GA, I/8, 249; Fichte, 1976, p. 75), ya que «no será intensamente atraída por ningún [objeto], ni lo penetrará también intensamente, pero hablará hoy de esa, mañana de aquella otra situada en la superficie, a tenor del capricho del momento» (GA, I/8, 249; Fichte, 1976, p. 75). En suma, no alcanzará estar de acuerdo consigo misma, pues sus fuerzas (disposiciones) estarán dispersas y sin encadenarse con su vida, lo que es el mayor indicio de tener delante de sí la condición para despertarse para la presencia de la idea, del concepto de la especie (imposible de ser obtenido 
de modo sensible), ya que el saber solo se torna claro si una luz se difunde sobre lo mismo.

Haciendo mención a la invención de la matemática Fichte destaca que la ciencia no ha sido cultivada desde siempre solo de un tal modo superficial como muestra en la tercera edad. Pero esa edad queda marcada por eso: en su exposición y comunicación, sea oral o escrita, no está presente el subyacente carácter orgánico del todo que promueve el enlace de la comunicación con la resolución y de la exposición con el retorno de todas sus partes hacia un término medio. Es decir, esa época no puede traer claridad en sus exposiciones, sino que le resta repetir lo mismo innúmeras veces. Y más que eso: no busca ofrecer nada que pensar al lector, ni pode estimular su actividad, pues semejante época no cree en esa clase de participación. Todavía, del mismo modo también han pasado otras épocas en que ni siempre pareció problemático «estimular el lector o el oyente», como lo demuestran las obras clásicas que están conservadas hasta hoy, y donde se sucedieran exposiciones con espíritu. Así, como un cierto sagaz de la época, Fichte identifica el actuante en la tercera edad: para que solamente ella reine y siempre desde sus productos, para derivar de ella misma «todos los honores» (GA, I/8, 250; Fichte, 1976, p. 76), hace suprimir las obras clásicas y disuadir el aprendizaje de las lenguas de ellas. Como conclusión se tiene entonces que esta es una época impregnada de un aburrimiento (tedio) infinito, pues solo con y por la idea (GA, I/8, 250; Fichte, 1976, p. 76) el espíritu puede ser llenado, satisfecho y feliz; solo la atención que se presta a la idea puede hacer posible vislumbrar el crespúsculo matinal de la nueva edad (GA, I/8, 248; Fichte, 1976, p. 74).

\section{La Educación delante de la tercera edad de la historia de la vida terrena}

Delante de lo visto se constata que el contenido comunicativo de la tercera edad está alejado de contacto directo con su fuente, la idea, pues no solo no la reconoce internamente, sino que expresa total resistencia a asimilarla como suya para entonces pasar por ella y llegar a una etapa siguiente. Con efecto, ¿de qué modo Fichte presenta la situación de la educación en ese período de transición de la tercera para la cuarta edad?

Es cierto que el tema de la Educación apareció en otros textos del mismo período, pero del punto de vista filosófico la tematización llevada a efecto en Los Caracteres... parece bastante apropiada por colocarla en una perspectiva más amplia que, por ejemplo, en los Discursos a la Nación Alema (1806), que se dedica a tematizarla en la perspectiva de los objetivos nacionales de la nación particular, la alemana, mientras que en los Grundzüge el interés es exponerla desde una perspectiva histórica universal. ${ }^{9}$ El tema de la educación en los Grundzüge hace hincapié en el

9 Según Janke, algo que se ha pasado por alto con frecuencia es que los Discursos a la Nación Alemana «están concebidos [...] como continuación de los Grundzüge. Según estos escritos, la nación alemana tiene su lugar histórico en un plan universal, en el que en cada época el pueblo 
impacto que tiene el contenido comunicativo no relacionado con su fuente en la expresión del tema de aprendizaje no vinculado a la idea. Y en ese debate aparece de nuevo, tal vez aún con mayor profundidad, el sentido del tema de la diferencia entre el espíritu y la letra, que la primera vez que reunió a Fichte y Schiller.

En la Sexta Lección de Los Caracteres de la Edad Contemporánea, en la exposición de las directrices sobre el modo justo de leer y pensar los escritos producidos por una cierta edad, en que el estado de la ciencia aún sea un estado como algo que debe ser, puesto que aún no lo es, concluyó Fichte: «Sabemos cómo ha debido razonar y decir, pues hemos comprendido su conjunto» (GA, I/8, 266; Fichte, 1976, p. 90). Además de incluir, en ese razonar, una comprensión del conjunto o visión de conjunto y del todo para tener bajo control la idea global de la obra, como había ya postulado Kant (en el Prefacio de la segunda edición de la Crítica de la razón pura), ${ }^{10}$ Fichte puso en marcha, en el texto de los Grundzüge (redactado entre 1804 y 1805 y publicado en 1806), la tarea de hacer comprender su época como perteneciente a la Edad de la humanidad de un tiempo muy apropiado, por él llamado de tercera edad, en contraste con una edad futura - la cuarta edad -, a ser aún producida por la pura razón.

Acá apuntamos hacia el elemento vinculante de las Lecciones Sexta y Séptima de los Grundzüge, en que la Educación a ser producida para la próxima edad será hay que ser - una que produzca el rescate de la aspiración científica de la edad que llama a nuestra puerta, cuyo comienzo debe entenderse como producido «de dentro hacia fuera y no a la inversa, de fuera hacia dentro» (GA, I/3, 89; Fichte, 2007a, p. 178 ), es decir, desde el espíritu. Para eso Fichte fue llevado a poner a su debido lugar el papel de la letra en esta edad futura (cuarta edad), contrastándola con el lugar por ella ocupado en la edad para él contemporánea, la tercera.

Transcurridos 10 años desde que se detuvo en la diferencia entre el espíritu y la letra en la filosofía (en la pelea con Schiller en el episodio de Las Horas), habiendo también sucedido el período del Atheismusstreit (1799-1800) y su ida a Berlín; el cambio de perspectiva del abordaje transcendental en la Doctrina da Ciencia Nova Methodo; su separación del trabajo colaborativo con Schelling (1802), el reemplazo del concepto del Yo por el concepto del Saber como distinto del Absoluto, iniciado con la Doctrina de la Ciencia 1801-02; la transfiguración del lugar de la Doctrina da

menos deteriorado en su naturaleza, lenguaje y religión es el que está llamado a aproximar a la humanidad a su fin, a saber, coordinar todas sus relaciones con libertad según la razón» (Introducción a la Doctrina de la Ciencia Nova Methodo, p. XVII).

10 Kant había dicho que, concerniente «a la naturaleza de una razón pura especulativa [...] esta posee una auténtica estructura en la que todo es órgano, esto es, una estructura en la que el todo está al servicio de cada parte y cada parte al servicio del todo [...]» y en que «el mero intento de modificar la parte más pequeña produce inmediatamente contradicciones, no solo en el sistema, sino en la razón humana en general», obteniendo-se de ahí su confianza, inspirada, dice él, en «la evidencia que ofrece el comprobar la igualdad de resultado, tanto si se parte de los elementos más pequeños para llegar al todo de la razón pura, como si se retrocede desde el todo (ya que también éste está dado por sí mismo a través de la intención final en lo práctico) hacia cada parte» (Kant, XXXVIIXXXVIII; Kant, 1997, p. 31). 
Ciencia en la Segunda Exposición de 1804, según la cual, como apuntó Ludwig Siep, el pensamiento de Fichte se mostró tan renovado a punto de escapar a todas las críticas que en el Differenzschrift (1801) le había direccionado Hegel (Siep, 1970); y, además de eso, aún concomitante a su exposición madura sobre la Doctrina de la religión (die Anweisung zum seligen Leben, 1806), como exposición popular de los principios desarrollados en la Doctrina de la Ciencia de 1804, hacia el tema de los Grundzüge Fichte evalúa lo que llamó - en las lecciones que la constituyen - la perplejidad causada por la tercera Edad.

La tercera edad se ha convertido, a pesar de haberse beneficiado del progreso técnico debido a la invención de la Imprenta, en la causa del retraso en el desarrollo de las conciencias debido al propio papel, que acepta todo. Debe recordarse - en el entonces 1794 - que Fichte había presentado la oposición entre los literalistas [geistlose Buchstäbler], partidarios de la letra - que poco caso o ninguno hacían del espíritu en la filosofía (cuyo único ingenio [Witz] es hacer juegos de palabras e indirectas) -, y aquellos que tienen espíritu o escriben con espíritu. Él había definido espíritu ahí como la facultad «de elevar sentimientos [en el recóndito representaciones] a la conciencia» (GA, II/3, 317; Fichte, 2007b, p. 137). Y observó que, a medida en que los sentimientos pueden referirse sea a la vida animal o a la vida racional-espiritual, esa facultad interesa verdaderamente y con exclusividad en ese último caso como «facultad de llevar ideas a la conciencia; una facultad de representarse ideales» (GA, II/3, 318; Fichte, 2007b, p. 139), mientras que, a su vez, la falta de espíritu «podría describirse como una incapacidad [Unfähigkeit] para la representación de ideales, una incapacidad que, por desgracia, siempre ha estado presente entre los hombres» (GA, II/3, 318; Fichte, 2007b, p. 139). Contrastado a los sentimientos que se refieren a la vida meramente animal del hombre («que no son muy profundos, no están en mucha profundidad, y elevarlos a la conciencia es la cosa más fácil» (GA, II/3, 318; Fichte, 2007b, p. 138), se destacan los sentimientos que tratan de la «mera representación de un mundo sensible de fenómenos bajo leyes naturales» (GA, II/3, 317; Fichte, 2007b, p. 138), a los cuales «les sirven de fundamento a su vez otros sentimientos que no se refieren a la vida meramente animal del hombre, sino a su vida racional y espiritual» (GA, II/3, 318; Fichte, 2007b, p. 138). Aquí se destaca marcadamente su efecto, pues, afirma Fichte,

más que referirse al simple orden de los fenómenos bajo leyes naturales, estos otros sentimientos se refieren a la subordinación de los fenómenos y de todos los espíritus a las leyes del orden ético [sittlichen], las leyes que gobiernan la armonía espiritual y la unificación [Vereinigung] de todos en un reino de la verdad y la virtud (GA, II/3, 318; Fichte, 2007b, p. 138-9).

En ese contexto nos alzamos a la mención hacia el espíritu, en las Lecciones Sexta y Séptima de los Grundzüge, con provecho de la paridad entre las concepciones de humanidad de Schiller y Fichte de aquellos años de pelea (1794). Por su propuesta de rescate de la «aspiración científica de la edad» (GA, 1/8, 263; Fichte, 1976, p. 
88), Fichte apunta ahora - en los Grundzüge - al movimiento que hay en el interior de la humanidad solo subjetivamente considerada, para rescatarle de su interior la humanidad objetiva, que también Schiller había propuesto con la colaboración de Fichte, como mencionó en la Carta IV de las ästhetischen Erziehungsbriefen, bajo la influencia recibida para la deducción del concepto de hombre puro e ideal, a la base del concepto empírico del hombre individual, en las Lecciones sobre el destino del sabio (1794).

Así como Schiller pensaba la idea del Estado como debiendo ser «una organización formada por sí y para sí, [y que] no podrá llegar a realizarse, sino cuando las partes se hayan acomodado a la idea del todo" (Schiller, 2000, S. 15; $\mathrm{s} / \mathrm{d}, \mathrm{p} .107)$, del mismo modo Fichte apunta, para que se dé la elaboración del concepto de humanidad objetiva, que sea llevado en cuenta el tipo de emulación ahí presente: ella es el resultado del trabajo del género humano, puesto que, dice él, «en el género humano el espíritu se desarrolla constantemente mediante esta lucha de unos espíritus con otros» (GA, II/3, 320; Fichte, 2007b, p. 142), en favor del cual «la especie entera se vuelve más espiritual» (GA, II/3, 320; Fichte, 2007b, p. 142) o la materia es a cada vez intelectualizada. Así que, continua Fichte, «con el primer intento burdo de comunicación espiritual el espíritu de las épocas futuras está [acá] preparándose a sí mismo» (GA, II/3, 320; Fichte, 2007b, p. 142).

En esas Lecciones el tema de la perplejidad de la tercera edad remite al modo actual para lograrse llegar a lo más esencial y más importante para la humanidad desde el punto de vista de la filosofía. Ya que no podríamos fiarnos en la mera invención de la Imprenta y al avanzo técnico como garantía de que todo saldrá bien en las ciencias; al contrario, muchos desabores han venido gracias al elevado valor que pasó a tener la letra (al papel que todo acepta) en ese período moderno, donde el hacer imprimir ganó por ende «un mérito en sí y por sí» (GA, 1/8, 260; Fichte, 1976, p. 85) en lo científico y en las artes de la palabra, dejando de interesar el fin [Zweck] «por lo cual se imprimía» (GA, I/8, 260; Fichte, 1976, p. 85)

¿En qué este diagnóstico permite ofrecer una solución para ese impase - si la meta es conducirse para la cuarta Edad, como la edad de la ciencia de la razón, de la ciencia real y verdadera? Fichte evalúa que la actitud de adjudicar a la palabra escrita el supremo fundamento decisivo de toda la verdad y como el único maestro del camino (a conducir a la bienaventuranza) - como ha dicho en la Lección Séptima coaduna acertadamente con la admisión del lado sólo formal de la ciencia y el grado de la consciencia en la edad anterior (tercera edad) (Lección Sexta). Y eso es el síntoma de una disfunción o inversión en que se ha convertido en fin [Zweck] lo que primero fue sólo un medio (GA, I/8, 273; Fichte, 1976, p. 97), como lo que retrata propiamente, dice, «el destino universal de todas las cosas humanas, después de haber durado algún tiempo» (GA, 1/8, 273; Fichte, 1976, p. 97).

Lo que se espera que suceda en la cuarta Edad es lo que falta (el motivo de la perplejidad) y de lo que carece la edad actual: la capacidad de comunicación oral 
[mündliche Mittheilung] y de ser comunicada según un grado de mejoramiento que ultrapase - supere, anule o contrarreste - el carácter meramente formal de la ciencia en ese período, es decir, de una actividad aún no completamente desarrollada, a la cual carece ser implantada. Pues, delante de ese nivel meramente formal de la ciencia, pregunta Fichte: ¿en qué se asientan los conceptos de la libertad de conciencia, de cátedra, de expresión del pensamiento? ¿De dónde surgen? (GA, I/8, 257; Fichte, 1976, p. 82) El «campamento solo formal de la ciencia» (GA, I/8, 259 y 260 ; Fichte, 1976, p. 84-85) ha proporcionado la oportunidad del asiento de la autoridad, de la fe ciega en la autoridad (GA, I/8, 256; Fichte, 1976, p. 81), vinculada al predominio de la letra (GA, I/8, 256; Fichte, 1976, p. 81). Según Fichte, ese terreno fue ganado por «el campamento de la ciencia formal» o para la ciencia meramente formal.

Aquí una pista puede ayudarnos, según corrobora Hannah Arendt acerca del rescate de la raíz de la «autoridad». Dice ella: «El sustantivo auctoritas deriva del verbo augere, «aumentar», y lo que la autoridad o los que tienen autoridad aumentan constantemente es la fundación» (Arendt, 1996, p. 133) Teniendo eso en cuenta, hay que ponderar con Fichte que con la fe ciega en la autoridad lo que ha sido aumentado fue solamente la capacidad de la Imprenta de expandirse y ganar más terreno, sin atención para aquello que estriba a su base.

El tipo de fundación con la cual se contentaron los hombres de esa tercera Edad fue el simple acto de apropiarse del arte del «concebirse en cuanto tal» (GA, I/8, 256; Fichte, 1976, p. 81) por sí mismos - lo que llamé arriba de humanidad sólo subjetiva (o Estado subjetivo) -, sin que pudieran elevarse a partir de ahí «por encima de algo que les enseñaron en la niñez» (GA, I/8, 255; Fichte, 1976, p. 80) y en virtud de la cual también ahora les será imposible inculcárseles, concluye Fichte. Para llegar a salir de esta ciega compulsión («cargada por el sentimiento opresor de su vaciedad» (GA, I/8, 258; Fichte, 1976, p. 83), de la fe ciega en la autoridad), el camino es encontrar la ciencia de la verdadera (entera) razón, es decir, de aquella razón que faculte la aprensión del todo del pensamiento o del pensamiento racional en su conjunto.

La Educación adentra en esa tarea ${ }^{11}$ - y por lo tanto en esas lecciones primero con el objetivo negativo, de constatar lo que parece haber sido confundido por adrede, la confusión entre «el mero saber» [Wissen] y el «hacer» [Machen].

11 Para un enfoque detallado sobre la Educación o la Pedagogía en Fichte, véase Toro (2008), (2009) y (2010). Sin embargo, en contraste con la propuesta de defender el carácter mesiánico de la Educación traída por el autor, hay que prestar atención a los dos diferentes enfoques de la Educación, uno externo y otro interno, con los que trata la Filosofía aplicada. En palabras de Lauth (1968, p. 46), se debe tomar la Educación no como «ciencia de la pedagogía, sino pedagogía como praxis del formar», razón por la cual, como praxis de la razón, ella debe conducir al estado de arte de la razón, asignada en los Grundzüge como quinta edad de la humanidad. En nuestra exposición trataremos exclusivamente el aspecto interno de la pedagogía, aquello que la hace dependiente del funcionamiento de la conciencia en el descubrimiento dentro de sí misma de su actividad autónoma y espiritual, es decir, de la comunicación oral en su reunión a la comunicación interna, como fuentes que tienen distintos alcances, uno histórico y otro religioso. 
Es decir, el carácter del «hacer» («hacer, hacer, esta es la cosa» (GA, I/8, 255; Fichte, 1976, p. 80)) no debe ser concebido solo como otro modo de aprender, sino como un modo de proceder que remonta a las bases (cimientos) y logre corregir el carácter abstracto (meramente formal) del concepto. Cabe a la Educación, como tarea positiva, quedar lista para «enjuiciar sobre este punto» (GA, I/8, 255; Fichte, 1976, p. 80) y conducir al integral y verdadero desarrollo de él, puesto que, hacia la comprensión conjunta de la relación entre el saber y el hacer, deben primeramente ser evaluados los principios de ese saber.

A la vez que ese saber no debe ser repetitivo y puesto a remolque de estamentos estanques, la perspectiva de la Educación que dé el pasaje de la tercera a la cuarta Edad deberá alcanzar, dice él:

a) evitar a que los niños leen de corrido;

b) evitar a que escriban hasta donde sea asequible;

c) y que se posea la ciencia de aquel estamento al cual se confía su educación (se posea una dogmática sistemática y tabular, cuando su educación se encomienda a los escolásticos, bajo el nombre de catecismo);

Para Fichte ese modo de proceder, como máximas de la educación popular, no es algo originario o algo que pueda conducir a los fundamentos: se trata antes de mera reacción, que oculta bajo sí misma la regla general como condición para que se manifieste esa reacción (GA, I/8, 255; Fichte, 1976, p. 80). Al par del peligro que ronda ese contexto, de que los hombres vengan a conducirse de modo a retornar siempre a una nueva autoridad (GA, I/8, 259; Fichte, 1976, p. 84), la tarea urgente es probar que el modo individual de reflexionar y pensar no debe ser visto como un progreso.

Fichte apunta como esencia de su diagnóstico que el hecho de ser aún un campamento de la ciencia formal, el modo individual de pensar solo consigue mostrarse ser aspiración a un saber universal. Así arrojar luces hacia la verdadera concepción de humanidad (o del destino de la especie, de la razón) es el camino para atravesar la tercera edad, haciendo apelo a la ciencia de la razón, en lugar de a las idiosincrasias humanas. ${ }^{12}$

12 Como Francis Bacon asignó en el Novum Organum con respecto a los ídolos (nociones falsas) de la Caverna, en el fragmento XLII (cuarenta y dos): «[...] son los ídolos del hombre individual, pues cada hombre tiene (además de las aberraciones comunes a la naturaleza humana en general) un antro o caverna individual [p. 87/88] donde se quiebra y desbarata la luz de la naturaleza: o por el temperamento propio y singular de cada uno, o por la educación y comercio con otros, o a consecuencia de la lectura de libros o de la autoridad de aquellos que cada uno respeta y admira, o motivado por la diversidad de impresiones, según que estas tropiecen con un espíritu predispuesto y dominado por las preocupaciones o con un espíritu ecuánime y reposado, o cosas por el estilo. De modo que el espíritu humano (tal como se dispone en cada uno de los hombres), es una cosa variable, sujeta a toda clase de perturbaciones y casi a merced del momento. Por eso dijo con razón Heráclito [Frag.2] que los hombres buscan las ciencias en sus mundos menores privados y no en el Mundo mayor y universal» (Bacon, 2003, pp. 87-88). 
Mientras que en esa tercera edad el hombre (la ciencia formal, la Imprenta) solo «se limita a recoger una gran riqueza de opiniones para un juego futuro» (GA, I/8, 259; Fichte, 1976, p. 84), trabajando en favor de un «gran depósito del general opinar» (GA, I/8, 259; Fichte, 1976, p. 84) (el reino de las opiniones) - logrando un lugar para sí aquél que opine como es debido, apto para ser el conductor de las masas -, pondera Fichte, la tarea es entonces arrancársele a esta edad de la perplejidad: aún que esa edad no esté preparada para juzgar en general sobre la importancia de las investigaciones o la verdad de sus afirmaciones que alcancen a todos, el medio para la salida de esta perplejidad (en el arte de la escritura y de la Imprenta) es reconocer ese reino de opiniones como resultante sólo de esa edad. Pues, ha sido inventado, según Fichte, «un medio para fijar el acto de opinar [...] [y] la opinión misma para documentarse acerca de lo opinado y del opinante» (GA, I/8, 259; Fichte, 1976, p. 84), obteniéndose - para remedio de la amnesia - un permanente recordatorio de lo que había opinado, en virtud de lo cual tiene destaque en ese campamento de la ciencia formal el lugar del lector; puesto que la anhelada independencia del espíritu no fue alcanzada en el interior de las «artes de la palabra hablada» (GA, I/8, 260; Fichte, 1976, p. 85), hay que se preguntar - y Fichte lo hice - sobre «el primer propósito al hacer imprimirse algo» (GA, I/8, 260; Fichte, 1976, p. 85). Aunque no se trate de que esa libertad venga para algunos de modo colectivo o mismo empaquetada, él reconoce que una cierta independencia fue sí resultado del registro de opiniones por el hacer imprimirse como prueba pública y documentación (aún que esas «opiniones que se parezcan nuevas y que pugnan por nuevas formas» (GA, I/8, 260; Fichte, 1976, p. 85) nada más son que un afán).

Sin embargo, tanto en la ciencia como en las artes de la palabra lo que merece salir a la luz, afirma, es la «expresión de una vida entera, dedicada de un modo [...] nuevo y original de la idea» (GA, I/8, 261; Fichte, 1976, p. 86). Para elemento mediador respecto a ese cambio - para salida de la perspectiva de la tercera edad - y para garantizar un común intercambio entre el lector y el escritor, Fichte propone el desarrollo de la comunicación oral. La ventaja de la comunicación oral (GA, I/8, 263; Fichte, 1976, p. 87) - por sobre las letras muertas (Platón, Fedro (274 a), 1988, p. 400) - es evidente por medio del discurso o del diálogo científico; el tornarse receptivo a esta forma de comunicación - hasta al nivel del arte, el arte de la comunicación oral (las actividades de seminarios en clase, los congresos con las ponencias, etc.) parece ser aquello particularmente instructivo al hombre. ¿En qué sentido? No solamente en que ella, la comunicación oral, es irreemplazable...

En su relato acerca del mito del surgimiento del lenguaje, en el Fedro de Platón, Sócrates contemporizó que estaba lista ya la constatación de ser una señal de decadencia sustituir la comunicación oral por la escritura, ${ }^{13}$ puesto que esta

13 Sobre la señal de decadencia de nuestra filosofía a respecto de la filosofía para los antiguos pondera Giorgio Colli: «Platón llama filosofía, amor a la sabiduría, a su investigación, a su actividad educativa, ligada a una expresión escrita, a la forma literaria del diálogo. Y Platón contempla con veneración el pasado, un mundo en que habían existido de verdad los sabios. Por otra parte, la 
había sido inventada justamente para tal. ${ }^{14}$ Obviamente la ponderación fichteana sobre el carácter previo de la comunicación oral se refiere a que la conciencia sea desarrollada respecto a lo que viene por primero: el lector debe, al sacar el discurso del papel - creyendo inicialmente cogerlo originariamente de allí - entenderle que reposa a su base justamente la comunicación oral.

De lo contrario él se perdería para la comunicación oral, a saber, «por dejarlo pasivamente delante de un discurso a lo cual le escapa la actividad de corrección viva» (GA, I/8, 263; Fichte, 1976, p. 88), mientras que, por otro lado, habiendo aprendido que lo impreso es solo medio, y no puede nunca ser considerado como un fin en sí (algo sustantivo en sí), abre precedente para otra vía: torna disponible al lector la instrucción para cambiar eso y asumir activamente el entero discurso en su proceso, «coger en una sola unidad y abarcar cada uno de los períodos» (GA, I/8, 263; Fichte, 1976, p. 88), haciendo valer la llegada del tiempo «de empezar algo nuevo», que es: «que se recoja de un lado el medio de la comunicación oral y se le desarrolle hasta la destreza, hasta el arte; por el otro, que se trate de adquirir receptividad para esta forma de la comunicación» (GA, I/8, 264; Fichte, 1976, p. 88)

El lector que ha convertido el discurso desde su estructura fijada en períodos para pensarlo antes en una estructura fijada (por primero cogida y entonces fijada) segundo una sola unidad, en lo cual quedan abarcados cada uno de los períodos ese lector se califica y se muestra en condiciones de comprender aquello que es la verdadera aspiración científica: él comprende - en el contexto de una edad entera - lo que diferencia las condiciones de imprimir y las condiciones de escribir (y de

filosofía posterior, nuestra filosofía, no es otra cosa que una continuación, un desarrollo de la forma literaria introducida por Platón; y, sin embargo, esta última surge como un fenómeno de decadencia, ya que 'el amor a la sabiduría' es inferior a la 'sabiduría'». Efectivamente, amor a la sabiduría «para Platón, significaba la tendencia a recuperar lo que ya se había realizado y vivido, y no aspiración a algo nunca alcanzado» (Colli, 1977, p. 11-12).

14 Así relata Platón en el Fedro: «Pero, cuando llegaron a lo de las letras, dijo [p. 402/403] Theuth: 'Este conocimiento, oh rey, hará más sabios a los egipcios y más memoriosos, pues se ha inventado como un fármaco de la memoria y de la sabiduría.' Pero él [Thamus] le dijo: ¡Oh artificiosísimo Theuth! A unos les es dado crear arte, a otros juzgar qué de daño o provecho aporta para los que pretenden hacer uso de él. Y ahora tú, precisamente, padre que eres de las letras, por apego a ellas, les atribuyes poderes contrarios a los que tienen. Porque es olvido lo que producirán en las almas de quienes las aprendan, al descuidar la memoria, ya que, fiándose de lo escrito, llegarán al recuerdo desde fuera, a través de caracteres ajenos, no desde dentro, desde ellos mismos y por sí mismos.» Cómo Emilio Lledó Íñigo comenta en la nota, la estructura ambivalente del pharmakon puede ser constatada «en los diálogos platónicos: Cármides 155e, Crátilo 394a, Protágoras 354a, Fedón 63d, República 469c, Timeo 89c, Leyes 649a. Y, visto que conocer es recordar (Menón 81b). Pero desde dentro, acá la exterioridad de la escritura y la insistencia en este hecho, alude a uno de los problemas esenciales de la 'pedagogía'.» Sigue el rey para Thamus: «No es, pues, un fármaco de la memoria [mnêmé] [p. 403/404], lo que ha hallado, sino un simple recordatorio [hypómnêsis]. Apariencia de sabiduría es lo que proporcionas a tus alumnos, que no verdad. Porque habiendo oído muchas cosas sin aprenderlas [àneu didachês/sin didáctica]", pues, comenta Î́nigo, «esta didáctica sería, pues, un elemento del proceso de interiorización que constituye la pedagogía 'viva', la que no presta sólo 'apariencia de sabiduría'»; esto es, concluye el rey: "parecerá que tienen muchos conocimientos, siendo, al contrario, en la mayoría de los casos, totalmente ignorantes, y difíciles, además, de tratar porque han acabado por convertirse en sabios aparentes en lugar de sabios de verdad» ( $275 \mathrm{~b}$ ). 
pensar).

Como elucidado en la Doctrina de la Ciencia de 1794, ${ }^{15}$ Fichte observó cómo haciendo parte del entendimiento la actividad de fijar; y a la imaginación transcendental el papel o la actividad de coger todo en una sola unidad. En ese contexto él propone como alternativa para esa época - en la salida de la tercera Edad - un modo de leer distinto del habitual, a saber, un modo de leer según el cual se extrae el espíritu de su letra, es decir, que una individualidad ideal - y no sensible hable como el espíritu del tiempo y en que las obras del tiempo se manifiesten como la propia ciencia (su estado) en cada momento actual del tiempo.

Puesto que el primer fin de la lectura es entender y conocer históricamente la intención del autor y el segundo fin, juzgar si esta intención es conforme a la verdad (lo cual sólo será posible después de un estudio tan penetrante), eso parece valer aquí, concerniente a las obras científicas, como reapropiación de lo ya dicho por Kant, de que «comparando los pensamientos expresados por un autor acerca de su tema, tanto en el lenguaje ordinario como en los libros, lleguemos a entenderle mejor de lo que él se ha entendido a sí propio» (GA, I/8, 265; Fichte, 1976, p. 90).

En ese dominio Fichte reinserta la noción de espíritu, ahora no solamente como la facultad de «llevar ideas a la conciencia; una facultad de representarse ideales» (GA, I/8, 318; Fichte, 1976, p. 139), en el sentido general, sino como la facultad de captar la intención del autor, de captarla el su conjunto en la totalidad de su obra, como espíritu de conjunto. Así que para Fichte el espíritu, como contenido oculto en el pharmakon platónico, en esa evaluación de la transición de la tercera para la cuarta edad, representa un cambio: a despecho de que para Platón el pharmakon representaba una estructura ambivalente (remedio o veneno, posibilidad de aclarar o de intoxicar), Fichte pondera que no nos engañemos más desde que se considere la base del pharmakon la comunicación oral, lo que había sido la señal de los sabios de antaño.

Fichte aplica en la Séptima Lección de Los Caracteres... lo que diagnosticó en la Sexta, desde la observación que permite una visión más completa de lo que estaba diciendo, es decir, que «en una misma edad pueden coexistir, e entremezclarse, y mezclarse partes integrantes de las más diversas edades» (GA, I/8, 268; Fichte,

15 En la explicación que elucida su concepción de las facultades, en la Grundlage (1794), Fichte afirmó ser necesarias tres cosas para fijación de un contenido vivo como lo de la intuición: 1) la acción de fijar o sujetar, pues «[...] el fijar acaece por espontaneidad para la reflexión [...]», y «[...] el acto de fijar corresponde a la facultad absolutamente ponente del Yo, o a la razón [...]»; 2) «[...] lo determinado o lo que deviene determinado - y se trata [...] de la imaginación, en cuya actividad es puesto un límite»; y lo que surge por determinación («el producto de la imaginación en su oscilación pendular»); 3) y, debiendo ser posible la fijación exigida, para esa fijación hay una facultad; entra en escena la facultad intermedia entre razón e imaginación (productora) «[...] es la facultad en la que lo que cambia subsiste (besteht) y se encuentra asimismo entendido $<$ (igualmente establecido como presente [zum Stehen gebracht])>, por lo cual se llama justamente entendimiento [Verstand]); «el entendimiento es entendimiento sólo en la medida en que algo es fijado en él; y todo lo fijado es fijado sólo en el entendimiento» (GA, I/2, 373-374. Fichte, 1975, 102). 
1976, p. 93). Tras subrayar el carácter transcendental de su perspectiva, partiendo de la base de que esta visión sobre las edades se produce acordada con la capacidad propia de la «naturaleza humana en general», y no con un ser externo que podría existir como exponente propio de cada edad, señalando así el elemento asintótico de la visión humana, evalúa que ha extraído el estado de las letras en la situación actual, en la tercera Edad, de una deducción racional y no de forma empírica.

En su análisis de la cuarta edad, con el objetivo de abrir el camino para exponer cómo debe ser el estado de la ciencia en el futuro, Fichte busca una brecha entre las dos edades para mostrar que la etapa misma de la tercera edad fue algo que también se logró y que, por lo tanto, no siempre fue así. Él procede en ese análisis por los datos históricos para comprobar lo que ha dicho; según él, los reformadores llevaron el camino a la tercera edad, produciendo un Teufelkreis, donde la Escritura, tomada para único fundamento decisivo, produjo el cuidado de que «la letra escrita encontró el alto y universal valor que tiene desde entonces» (GA, I/8, 273; Fichte, 1976, p. 98), es decir, por el Cristianismo «suscitado por el Protestantismo, fundado en la Biblia» (GA, I/8, 273; Fichte, 1976, p. 97).

Al exigir al adversario (Protestantismo) «el principio [...] negado por él» mismo (GA, I/8, 273; Fichte, 1976, p. 97) - el Catolicismo (que «puso término [...] a la exigencia de pensar y concebir por uno mismo» (GA, I/8, 272; Fichte, 1976, p. 96)) ha allanado el camino para el apelo al pueblo en apoyo de la causa de la Reforma Protestante. ${ }^{16}$ Así, como acto para contornar la no-aceptación de esa causa, por parte del público docto y versado, los reformadores llegaron a «ponerle en las manos la Biblia, traducida a su lengua» $y$, en lo sucesivo, que el pueblo fuera requerido para leerla (a) y fuera requerido para juzgar por sí mismo si se hallaba o no, realmente en ella, con claridad, lo que los reformadores encontraban en ella (b). Por el derecho que se le concedía el pueblo se encontró entonces aleganado y de él se sirvió todo lo que le fue posible. Y los príncipes no se opusieron o buscaron medios contra eso: no impidieron que las traducciones de la Biblia y las obras de los protestantes cayeran en manos de la gente y del pueblo, razón por la cual la Reforma puede apoderarse de toda la Europa cristiana. Es decir: el propio protestantismo, por su cuidado por el cristianismo, fundado en la Biblia, ha fornecido el modelo hacia el alto y universal valor que tiene «la letra escrita». Y a la vez, el alto valor que llegó a tener a letra aún hacía referencia al nuevo gnosticismo, que quería todo asentar y explicar (la Biblia) de modo puramente racional, haciendo oposición a las doctrinas cristianas de la iglesia (catolicismo) y al protestantismo.

Según Fichte, seguirá de aquí la bifurcación del camino en el establecimiento de la teología cristiana por la forma del Evangelio de Juan y la del Pablo: es la forma del Evangelio del primer que apunta al camino a que se debe llegar - la cuarta edad - como camino que conduce a la bienaventuranza, puesto ser el de la ciencia real y verdadera como ciencia de la razón, en que suele bastar la evidencia íntima,

16 Para un enfoque histórico contemporáneo sobre la Reforma Protestante, véase Elton, 1974. 
subministrada directamente por el espíritu. Es decir, llevada a su verdadero plan, la capacidad de comunicación oral [mündliche Mittheilung] como comunicación de una interioridad, en ello lo presentado por la doctrina de Juan se aproxima a las teses metafísicas de la Doctrina de la Ciencia de 1804. A su vez, la forma del Evangelio de Pablo apunta al estacionamiento en la tercera edad como una edad aún sin espíritu, puesto que mantiene la palabra escrita como fundamento decisivo de toda la verdad y como el único maestro del camino.

La tarea de percibir el cambio entre las distintas edades como algo que ocurre también a través de la emulación del trabajo del género humano, por la cual se desarrolla constantemente el espíritu mediante esta lucha «de unos con otros» (GA II/3, 320; Fichte, 2007b, p. 142) significa un paso en favor de que la palabra sea cada vez más intelectualizada (y que la especie entera se vuelve más espiritual), es decir, tenga su fundamento en la idea, como la verdadera interioridad, aquella en que la especie aparece en su lugar fundante. Aún en eso hay la señal de la presencia de la cuarta edad en la tercera, ya que pueden coexistir «en una misma edad [...] partes [...] de las más diversas edades» (GA, 1/8, 206; Fichte, 1976, p. 93), sea percibida como dependiente, en particular, de la facultad de captar la intención del autor en las ciencias e en las artes, de captarla en su conjunto y en la totalidad de cada obra, como verdadera señal en la Imprenta de que el espíritu de las épocas futuras «está preparándose a sí mismo» (GA II/3, 320; Fichte, 2007b, p. 142) aquí y ahora.

En la producción en Berlin Fichte ha hecho suceder al texto de los Grundzüge, y vinculado al debatido en la Séptima Lección, el texto de La Exhortación a la vida bienaventurada [Anweisung zu seligen Leben], en cuyas Sexta y Undécima Lecciones profundizó el tema de la comunicación (interior) y de la evidencia interna, que está estrechamente relacionado con el tema de la comunicación oral o el acceso al espíritu que subyace en el texto escrito. Veamos eso a continuación.

\section{La ley de la razón y las tradiciones del espíritu (Juan) y de la palabra}

En el contexto de Anweisung, en relación con lo que señalé anteriormente en la Séptima Lección de Los Caracteres..., juega un papel fundamental el evangelio de Juan. Dice Fichte:

En las lecciones del pasado invierno [a saber, en las que se presentaron Los Caracteres de la Edad Contemporánea] di ya la razón de por qué yo tengo a Juan Evangelista por el maestro del auténtico cristianismo. [...] Solo con Juan puede concordar el filósofo, ya que solo este tiene respeto por la razón y se atiene a la única demonstración que el filósofo da por válida: la [demonstración] interna (GA, I/9, 116; Fichte, 1995, p. 106).

Ha sido puesto en destaque, como elemento común en nuestro recorrido, la dificultad de la tercera edad en tratar con el contenido comunicativo de los trazos fundamentales de la edad, en general, a partir de su modo propio de ver: las ciencias, las artes, las relaciones sociales del hombre, la moralidad y la religión. Se presentó anteriormente 
el movimiento de oscilación de esa edad, que vacila en hacer el pasaje de la tercera a la cuarta edad y que no acepta, sino rechaza la idea de la especie como lo primero a buscarse hacia el individuo, en vista de salir directamente para privilegiar la individualidad sensible en el hombre.

También en la religión se observan ${ }^{17}$, por lo tanto, características semejantes con respecto del comportamiento establecido en la tercera edad: relativamente a ella se produce al par, a partir de la superstición, una inversión, en que asumen no solamente representaciones sensibles, sino vale la máxima de hacer valer lo que simplemente logra concebir. Allende semejante inversión vincularse a la carencia de concepto por reproducir meramente representaciones no vinculadas a la idea, hay aún el desprecio (desprecio incondicional) por la religión debido al no querer desafiar ciertas verdades que se imponen por su grado de pureza y clareza: si desde el punto de vista de la historia de la vida humana en la tierra lo objetivo fuera organizar todas sus relaciones con la libertad de acuerdo con la razón, en la religión ese objetivo es, del punto de vista de todos los impulsos y movimientos del hombre (individualidad), «mejorar sus circunstancias exteriores» (GA, I/9, 184; Fichte, 1995, p. 202). Por ende, para Fichte, un adecuado entendimiento de la religiosidad pasa necesariamente por comprender la comunicación en su posible interioridad. (GA, I/9, 175; Fichte, 1995, p. 189-190), visto que desde ella se establece el fundamento seguro para el pasaje a la próxima edad.

Mediante el par pasividad-actividad Fichte tematizó en la Anweisung el vínculo de unión entre el emisor y el receptor de una doctrina (que a la vez puede extenderse a un mensaje o una lección). Del punto de vista de ese trazo particular, la religiosidad, se establece para el que se comunica el problema de la insuficiencia en la interioridad del receptor, que se da cuando uno, por un lado, «no se entrega, como debería, a la lección con todo el espíritu, sino quizá solo con el entendimiento y la fantasía. [...] Y por otro, por la máxima dominante en la época de no querer tomar partido, y no decidirse ni a favor ni en contra; modo de pensar que se llama escepticismo [...]» (GA, I/9, 176; Fichte, 1995, p. 191). Mientras que el en primero se pasa por alto la lección por el hecho de haber sido estimulado a sí mismo el receptor solamente el en apetito de saber o apetito de novedad, indiferente por lo demás acerca de si el contenido se muestra de un modo y de otro, concerniente al entendimiento y a la fantasía la entrega del receptor tiene en vista el disfrute «meramente de la serie de imágenes, de manifestaciones, de palabras que agradan y modos de hablar» desplegados de la fantasía, «indiferente por lo demás acerca del contenido». (GA, I/9, 176; Fichte, 1995, p. 191).

Es decir, royendo la indiferencia sobre el contenido y desarrollando atención solo por la corrección de la forma, el propio entendimiento es tomado desde una consideración fría e indiferente, sobre la cual todo desarrollo efectivo de la ciencia

17 Para un contraste sobre la tematización de la religión desde la disputa entre Fichte y Schelling, véase Utteich, 2019. 
habrá de pasar. Concerniente a la máxima de no querer tomar partido, esa tiene directa relación con el grado «más profundo de la dispersión del espíritu [...] donde el hombre no es capaz de preocuparse sobre su propio destino» (GA, I/9, 177; Fichte, 1995, p. 191-192) y, en una perspectiva aún peor, tiene relación con «la opinión [...] brutal de que la verdad no es un bien y que nada yace en el conocimiento de ella» (GA, I/9, 177; Fichte, 1995, p. 192). Se trata ahí de un sentido obtuso para las cosas, cuyo grado máximo revela no ser posible un acuerdo de que «hay verdad, de si ésta es alcanzable por el hombre, y si es un bien» (GA, I/9, 177; Fichte, 1995, p. 192).

Y así como han sido para el propio Fichte - serán para los demás hombres -, las condiciones para «estar convencido de haber comprendido por sí mismo esa verdad a partir de un cierto estadio propio y un cierto grado de claridad», se requiere primero estar cierto de que hay verdad y que ella es concebible al hombre "y que es claramente concebible por él» (GA, I/9, 177; Fichte, 1995, p. 192). De modo breve, tales son las circunstancias de la época que se muestran obstáculos para una comunicación interior, mientras que «se los encuentran uno siempre de nuevo frescos y renovados, incluso en aquellos que tienen fuerzas y ganas de elevarse sobre ellos» (GA, I/9, 179; Fichte, 1995, p. 194). De este modo, completa él: «toda religiosidad permanece atrapada en la superficie de las cosas y en la apariencia vacía, e que, por tanto, presupone una carencia de fuerza y de energía del espíritu, a lo que necesariamente conduce la debilidad, tanto de la cabeza como del carácter» (GA, I/9, 181; Fichte, 1995, p. 197).

Hacia el punto de vista de las bases inspiradoras para la comunicación interior, Fichte hace referencia a la figura de Juan y de su evangelio (a su modo de expresar que Theos Agapé estin, Dios es amor), en contraposición a la teología de Pablo. Sin adentrar acá en el intrincado del atrito de Fichte contra aquellos que toman las

expresiones más serias y categóricas de este escritor [Juan] por meras imágenes y metáforas y las explican según ellas, hasta que no queda más que trivialidad y superficialidad, tal como estos mismos intérpretes las habrían podido encontrar y presentar (GA, I/9, 116; Fichte, 1995, p. 107),

interesa percibir la razón por la cual Fichte encuadra a todos los contemporáneos («la mayoría de los contemporáneos se pueden comparar entre sí, y estos de nuevo con un público sabio, precediéndolos y siguiéndolos [...]» (GA, I/9, 116; Fichte, 1995, p. 107) cuando busca avaluar el novedoso de lo traído por el evangelio de Juan. Pues, observa él, «el cristianismo y, muy especialmente, Juan permanecen desvinculados, como una manifestación temporal maravillosa y misteriosa, sin precursores ni auténticos sucesores» (GA, I/9, 117; Fichte, 1995, p. 107-108). Es decir, hay algo en la doctrina de Juan que «es verdadero en sí, absolutamente y válido para todo tiempo» (GA, I/9, 117; Fichte, 1995, p. 108).

La antes mencionada relación de unión entre el emisor y el receptor ilustra también el modo por lo cual Juan extrajo su doctrina desde la atención dedicada a 
escuchar y a oír las palabras de Jesús y en seguida explicarlas. ${ }^{18}$ Es decir, la doctrina de Juan está redactada de tal modo (su uso de la palabra está puesto de tal manera) que esa doctrina no es de Juan, sino del propio Jesús. Dice Fichte:

El autor, a lo largo de todo el evangelio, introduce a Jesús como hablando de sí de una cierta manera, que luego diremos. Y es sin duda el convencimiento de Juan que Jesús, y no otro, ha hablado, y que él lo ha oído hablar. Y su más seria voluntad es que nosotros debemos creerle. Ahora explica el prólogo la posibilidad de cómo ha podido Jesús pensar y hablar de sí, de cómo habla él de sí. Por tanto, es necesario el supuesto de Juan de que no solo él, este Juan, para sí mismo y según su mera opinión, quiere explicarse y comprender Jesús, sino que el mismo Jesús se ha pensado y comprendido tal como él [Juan] nos lo muestra. [...] Tampoco el prólogo, según la interpretación de Juan, es la doctrina de Juan, sino la de Jesús. Y concretamente el espíritu y la raíz más íntima de la doctrina completa de Jesús (GA, I/9, 117; Fichte, 1995, p. 108-109).

Así pasa a hacer parte de lo recorrido por el hombre individual una verdad que tanto Juan como Jesús (como «carne y existencia personal sensible y humana») (GA, I/9, 120; Fichte, 1995, p. 113) inculcan, y que se muestra opuesta a la fe meramente histórica (GA, I/9, 126; Fichte, 1995, p. 120), cuyo comienzo tiene inicio en la escisión que la perspectiva de Pablo ha causado respecto de los judíos.

En el fondo, para asentar el carácter previo de la comunicación interior Fichte hace hincapié sobre la imposibilidad de utilizarse medios lógicos exteriores para forzar a la comprensión: se trata de que esta y «el convencimiento solo surgen de lo más íntimo de la vida y de su amor» (GA, I/9, 178; Fichte, 1995, p. 194). Por el contenido del prólogo del Evangelio de Juan se puede comprender, asegura él, «Cómo la humanidad completa procede de la esencia divina», del mismo modo se comprende la hipótesis de «cómo el individuo Jesús, como individuo, ha procedido de la esencia divina» (GA, I/9, 189; Fichte, 1995, p. 209). Recordemos parte del prólogo:

En el principio existía la Palabra

la Palabra estaba junto a Dios, y la Palabra era Dios.

Ella estaba en el principio junto a Dios.

Todo se hizo por ella,

18 Es sabido que Fichte ha frecuentado estudios teológicos en su juventud en Jena, Leipzig y Wittenberg. Como observa Ivaldo (2003, p. 97), en recordación del propio hijo, Immanuel Hermann, Fichte había hecho la confesión de que «todas as sus pesquisas filosóficas tenían partido originariamente 'de la exigencia de constituir-se una dogmática sustentable' y que, por lo tanto, la razón para esta sería que él había tropezado «en puntos obscuros en la teología de su tiempo, a propósito de las doctrinas fundamentales de las propiedades de Dios, de la creación, de la libertad». En vista de ello es que, completa Ivaldo, él «se percatara la necesidad de pasar 'del punto de vista teológico al filosófico' - en las palabras del propio hijo - para encontrar un abordaje más adecuado de esos temas teológicos» (ídem, ibídem). Por lo tanto, así como concluye Marco Ivaldo al decir que la filosofía de Fichte tiene "proveniencia teológica», a partir de la influencia que sobre él tiene la doctrina de Juan se puede asentar aún que ella busca sobre todo partir del puro Espíritu (o de la Palabra, del Logos) y hacia él retornar. 
y sin ella nada se hizo.

Lo que se hizo en ella era la vida, y la vida era la luz de los hombres;

y la luz brilla en las tinieblas, y las tinieblas no la vencieron.

[...]

La Palabra era la luz verdadera que ilumina a todo hombre, cuando viene a este mundo.

En el mundo estaba, Y el mundo fue hecho por ella, pero el mundo no la conoció.

Vino a los suyos, mas los suyos no la recibieron.

Pero a todos los que la recibieron les dio poder de hacerse hijos de Dios, a los que creen en su nombre;

estos no nacieron de sangre, ni de deseo de carne, ni de deseo de hombre, sino que nascieron de Dios.

Y la Palabra se hizo carne y puso su Morada entre nosotros, y hemos contemplado su gloria, gloria que recibe del Padre como Unigénito, lleno de gracia y de verdad. ${ }^{19}[. .$.

A partir de ahí Fichte tematiza la imposibilidad del modo de pensar propiamente humano explicar la existencia por un interés cognitivo. El hombre tiene que alcanzar el modo de comprender su procedencia divina solamente por una comunicación interna (realidad interna, no lógica, más asentada en el sentimiento del amor, como amor a Dios y sacrificio de su propia vida personal exterior, en cuanto su identidad con Dios es entrega y amor a la especie). A diferencia del humano, Jesús por su propia existencia poseía su conocimiento - «que todo ser solo se fundamenta en Dios y procede inmediatamente de Él» (GA, I/9, 191; Fichte, 1995, p. 212) -; la existencia «era para él lo primero y lo absoluto, sin otro miembro con el que entrara en relación: sólo por inspiración [durch Inspiration]» (GA, I/9, 191; Fichte, 1995, p.

19 Biblia de Jerusalén, 2018, p.1542-1543. 
212). Todavía, hace necesario al filósofo transcendental buscar alcanzar por mediación lo autoconocimiento como verdad racional pura y absoluta, «salida genéticamente a partir de otro estadio» (GA, I/9, 191; Fichte, 1995, p. 212), por lo tanto, por medio de un concepto general.

En ese sentido se constata en el carácter del Jesús juánico, dice Fichte, que no quiera saber nada de tal escisión (lo tener que haberse separado de Dios) «de su persona respecto de su Padre, y a quienes lo intentan hacer les reprende» (GA, I/9, 192; Fichte, 1995, p. 213-214), pues lo «haberse puesto escindido, y maravillarse acerca de sí mismo» le entendió de manera equivocada, pues el hecho es que «no hubo un Jesús independiente», sino un todo-uno: «era Dios-Jesús, que apareció como Jesús» (GA, I/9, 192; Fichte, 1995, p. 214).

Visto que esa verdad Jesús la sabía de modo inmediato (por su propia existencia), no es posible de ser comunicada exteriormente. Por eso el único camino es profundizar el medio de entrar en la interioridad y en ella realizar la comunicación. Relativo a eso Fichte elucida la diferencia entre dos modos de pensar, uno activo y otro pasivo: el primero, el que hace una «vuelta y recogimiento en el uno» (GA, I/9, 130; Fichte, 1995, p. 124) y que para tanto presupone la conciencia inmediata de la energía interior espiritual, como siendo ese «comprenderse y contraerse de un espíritu disperso en un punto, y como el fijarse en este punto su unidad» (GA, I/9, 130; Fichte, 1995, p. 125). Y su contrario, el pasivo como el de quien se fija «más en los múltiples objetos exteriores sobre los que se dispersa» (GA, I/9, 116; Fichte, 1995 , p. 125) mientras la conciencia inmediata del hombre convierte ahí las condiciones de ser independiente y viene a ser dependiente, se presenta él por ende, solo "como una composición casual de la naturaleza», es decir, llega a una dispersión y a perderse «no de una manera que él quiera y se haga a sí mismo [...] sino de una manera en que él es hecho y en que la pasividad sin ley e incomprensible lo hace» (GA, I/9, 116; Fichte, 1995, p. 124). Concierne al modo de pensar activo, que presupone el «comprenderse y contraerse de un espíritu disperso en un punto, y como el fijarse en este punto su unidad» como siendo la conciencia inmediata de la energía interior espiritual, que se interprete y entienda la tesis de que desde siempre «Dios era la Palabra» o que Dios era la Razón. Pregunta-se Fichte: «¿Qué es, según la intención del autor, este Logos, esta Palabra? [...] Era al comienzo, dice; era en Dios; era el mismo Dios; era al comienzo en Dios» (GA, I/9, 118; Fichte, 1995, p. 110). Es decir, Dios era la Palabra, y a través de ella están hechas todas las cosas. Afirmar eso es, según Fichte, lo mismo que decir: «Dios no creó, ni necesitaba de ninguna creación, sino que ya era» (GA, I/9, 118; Fichte, 1995, p. 110).

Por eso, «respecto de una doctrina religiosa, la afirmación de una creación es el primer criterio de falsedad. [Y] La negación de tal creación, ha sido afirmada por una doctrina religiosa precedente, es el primer criterio de verdad de esta doctrina religiosa» (GA, I/9, 118; Fichte, 1995, p. 109). Así cabe a Juan, «el conocedor originario» del cristianismo, la evidencia de «la absoluta unidad e inmutabilidad 
de la esencia divina en sí misma» (GA, I/9, 118; Fichte, 1995, p. 109), razón por la cual es por un acceso exclusivamente interior que se concluye que «la existencia inmediata de Dios es necesariamente consciencia, en parte de sí mismo, en parte de Dios» (GA, I/9, 119; Fichte, 1995, p. 111). De ahí que sólo si se entrega a la doctrina con todo el espíritu puede el hombre ascender al interior del sí mismo como hogar del Ser uno (Dios), por medio de su existencia y de sus manifestaciones, y por el modo de pensar correcto entrar con eso en comunión con lo divino.

\section{Conclusión}

Vimos en el primer apartado que el tema de la historia reservó la tarea de aniquilar la vida sensible individual como medio de el hombre hacer racionalmente (conscientemente) parte de la idea y, con eso, del desarrollo de la especie, en cuanto que apareció como subyacente a los actos del aprendizaje en la Educación la noción de espíritu como actividad corriente proveniente del flujo verdadero de la comunicación oral. A su vez en el último apartado vimos que para comprender en su esencia la religiosidad como uno de los trazos fundamentales de la época, que el hombre podía alcanzar solo interiormente la forma de comunicación que es por sí mismo el amor, ya que el hombre no necesita de un Dios fuera de sí. Por eso, como medio para entregarse y sacrificarse a la especie, a fin de poner en práctica la Palabra, la Razón o Dios, le fue exigido ese carácter original espiritual que tiene sus anclas en la idea, más claramente expresa por Juan, que Dios es y se exprime por esa íntima y directa unión o comunicación interior que se llama amor. Así, desde un punto muy particular, la Educación demostró ser ante todo una tarea interna, como una praxis del formar que depende del espíritu como la originalidad viviente que funda todo lo que puede ser registrado, sea por escrito, sea por la Imprenta, y que en eso puede poner a la humanidad en el acceso al ser espiritual que se da en la comunicación interna.

\section{Referencias}

Arendt, H. (1996). Entre el pasado y el futuro. Ocho ejercicios sobre la reflexión política. Trad. Ana Poljak. Barcelona: Península.

Bacon, F. (2003). Novum Organum. Trad. Clemente F. Almori. Buenos Aires: Losada. Biblia de Jerusalén. (2018). Nueva Edición. Bilbao: Desclée De Brouwer.

Colli, G. (1977). El nacimiento de la Filosofía. Trad. Carlos Manzano. Barcelona: Tusquets.

Elton, Geoffrey R. (1974). La Europa de la Reforma (1517-1559). Trad. Jesús Fomperosa. Madrid: Siglo XXI.

Fichte, J. G. (1962-1991). Gesamtausgabe der Bayerischen Akademie der Wissenschaften. Reinhard Lauth, Erich Fuchs, Hans Gliwitzky und Peter K. Schneider (Hrsg.). Stuttgart/Bad-Cannstatt: Frommann, 42 Bänden. 
Fichte, J. G. (1975). Fundamento de toda la Doctrina de la Ciencia (como manuscrito para sus oyentes). Trad. Juan Cruz. Argentina: Aguilar.

Fichte, J. G. (1976). Los Caracteres de la Edad Contemporánea. Trad. José Gaos. Madrid: Revista de Occidente.

Fichte, J. G. (2002). Algunas Lecciones sobre el destino del sabio. Trad. Faustino Oncina Coves y Manuel Ramos Valera. Madrid: Istmo.

Fichte, J. G. (2007a). Sobre el Estímulo y el Incremento del puro Interés por la Verdad. Trad. Manuel Ramos y Faustino Oncina. In: Filosofía y Estética (pp.169180). Colección estética \& crítica. Valencia: Universidad de Valencia.

Fichte, J. G. (2007b). Sobre la Diferencia entre el Espíritu y la Letra en la filosofía. Trad. Manuel Ramos y Faustino Oncina. In: Filosofía y Estética (pp.135-167). Colección estética \& crítica. Valencia: Universidad de Valencia.

Girndt, H. (1990). Die fünffache Sicht der Natur im Denken Fichtes. Fichte-Studien, 1, 108-120.

Girndt, H. (2002). Quintuplicity in Fichte's Philosophy. In: Gil, F.; López-Domínguez, V.; Soares, L. S. Fichte: Crença, Imaginação e Temporalidade. Porto: Campo das Letras, pp. 253-262.

Ivaldo, M. (2003) Johann Gottlieb Fichte. Jesús “punto fundamental y punto de unidad da historia" (Staatslehre 1813). In: Zucal, S. (org.). Cristo na Filosofia Contemporânea. Vol. I: De Kant a Nietzsche. Trad. José R. Vidigal. São Paulo: Paulus, pp. 95-122.

Janke, W. (1987). Introducción a la Doctrina de la Ciencia Nova Methodo. In: Fichte, J.G. Doctrina de la Ciencia Nova Methodo. Trad. José L. Villacañas y Manoel Ramos. Valencia: Natan.

Kant, I. (1902). Akademie Ausgabe (AA) (Kants gesammelte Schriften: herausgegeben von der Deutschen Akademie der Wissenschaften). Berlin: Walter De Gruyter.

Kant, I. (1986). En torno al tópico: “Tal vez eso sea correcto en teoría, pero no sirve para la práctica”. In: Teoría y Práctica. Trad. M. Francisco P. Lopez y Roberto R. Aramayo, pp. 03-60.

Kant, I. (1997). Crítica de la razón pura. Trad. Pedro Rivas. Madrid: Alfaguara.

Lauth, R. (1962). Le problema de l'intersubjetivité chez Fichte. Archives de Philosophie, 25, 325-344.

Lauth, R. (1968). La Filosofía de Fichte y su significación para nuestro tiempo. Trad. Barnabé Navarro B. Universidad Nacional Autónoma de México.

Marin, V. S. (2019). Ética y Filosofía de la historia en Fichte. Pensamiento, 75(284), 621-638.

Market, O. (1980). Fichte y Nietzsche. Reflexiones sobre el origen del nihilismo. Anales del Seminario de Historia de la Filosofía, 1(1), enero, 105-119.

Ortega Y Gasset, J. (1958). Kant. Hegel. Dilthey. Madrid: Revista de Ocidente.

Platón (1988). Fedro. Trad. Emilio Lledó Íñigo. Barcelona: Gredos.

Schiller, F. (2000). Ueber die ästhetische Erziehung des Menschen in einer Reihe von Brifen. Stuttgart: Reclam. 
Schiller, F. (s/d). Sobre la Educación Estética del Hombre. Trad. Manuel G. Morente. Madrid: Tecnos.

Schnädelbach, H. (1991). Filosofía en Alemania (1831-1933). Trad. Pepa Linares. Madrid: Cátedra.

Sisto, M. (2009a). El "aporte” de Herder en 1774, y sus ideas (1784-1791). In: Brauer, D. (ed.). La historia desde la teoría. Vol. 1. Buenos Aires: Prometeo, pp. 255-285.

Sisto, M. (2009b). Plan humano y plan divino. In: Brauer, D. (ed.). La historia desde la teoría. Vol. 1. Buenos Aires: Prometeo, pp. 225-253.

Toro, G. L. (2008). La educación como labor mesiánica, según el filósofo alemán, Juan Teófilo Fichte. (Primera Parte). Revista Educación y Desarrollo Social. Bogotá. vol. 2, n. 2, julio-diciembre, 143-155.

Toro, G. L. (2009). La educación como labor mesiánica, según el filósofo alemán, Juan Teófilo Fichte. (Segunda Parte). Revista Universidad Militar "Nueva Granada", julio-diciembre, 148-163.

Toro, G. L. (2010). La educación como labor mesiánica, según el filósofo alemán, Juan Teófilo Fichte. (Parte Final). Revista Universidad Militar "Nueva Granada", 4(1), 168-183.

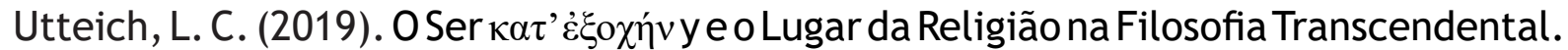
In: Ferrer, D. (org.). A Filosofia de História e da Cultura em Fichte. Coimbra: Imprensa da Universidade de Coimbra, pp. 59-86. 